\title{
Resenha: Um tipo diferente de animal: como a cultura transformou nossa espécie
}

\section{Revisión: un tipo diferente de animal: cómo la cultura transformó nuestra especie}

\section{Review: A different kind of animal: how culture transformed our species}

BOYD, Robert. A different kind of animal: how culture transformed our species. Princeton University Press, 2017. $248 \mathrm{p}$.

Piotr Tryjanowski piotr.tryjanowski@gmail.com Universidade de Ciências da Vida de Poznań, Polônia

Martin Hromada hromada.martin@gmail.com Universidade de Presov, Eslováquia

Fabio Angeoletto fabio_angeoletto@yahoo.es Universidade Federal de Mato Grosso, UFMT, campus de Rondonópolis, MT

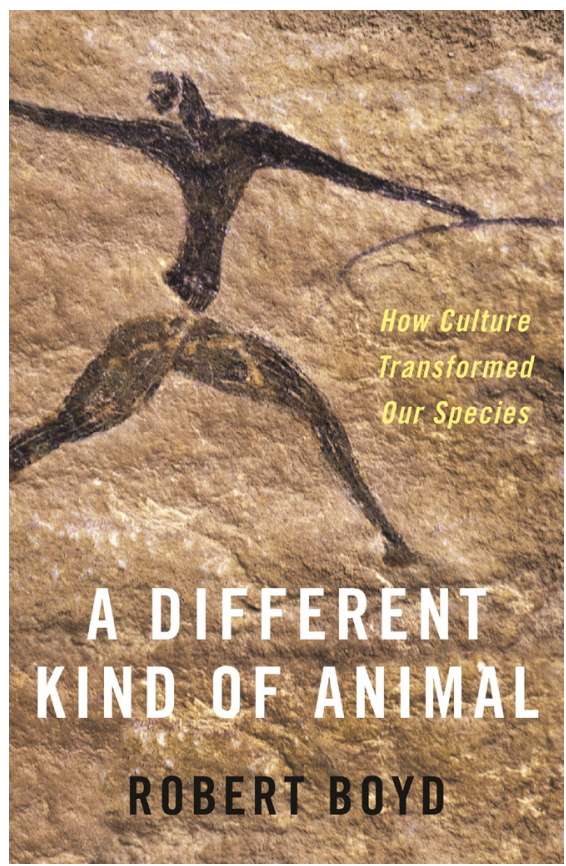


As cidades não são o oposto da natureza, mas uma notável expressão da nossa biologia. As urbes são a mais complexa invenção dos primatas humanos, essas curiosas criaturas que amalgamam biologia e cultura de maneira indestrinçável e sinérgica. Cidades são ecossistemas que, pela pouca produção fotossintética, dependem de imensas áreas externas para obtenção de matérias-primas e energia, e para a deposição dos resíduos gerados pela produção e consumo de produtos tão diversos como livros, gastronomia japonesa, gasolina, sexo virtual, ou viagens planetárias. Delas se originam impactos como câmbios nos ciclos biogeoquímicos, mas também nelas são gestadas ideias, tecnologias e soluções que podem ser adotadas mundialmente. Neste extraordinário ponto de viragem da odisseia humana, o século 21 ficará marcado na História como o momento em que a humanidade vive majoritariamente em cidades. Como chegamos até aqui?

Há muito tempo a singularidade do homem vem sendo enfatizada. Foi mencionado que outras espécies não fazem ferramentas, não produzem cultura, não têm personalidade, e não são capazes de ensinar intencionalmente. Descobriu-se, no entanto, que este não é o caso. Hoje sabemos que os animais conhecem os fundamentos da cultura, da linguagem e até da política. O que significa ser Homo sapiens? Alguns antropólogos e biólogos modernos evitam essas questões. Por outro lado, muitos representantes das ciências sociais ignoram a bagagem evolutiva dos seres humanos. Poderíamos supor que no processo de desenvolvimento das sociedades e adaptação às condições locais, a cultura superou a evolução baseada apenas em fatores naturais? Por exemplo, por que o cristianismo triunfou em Roma, enquanto os gentios sustentavam o culto à força e à saúde? Os cristãos foram perseguidos em um número inimaginável de maneiras, excluídos das suas comunidades, e ainda assim por que o poder de sua influência foi tão imenso? Tais perguntas podem ter sido formuladas por sociólogos da religião ou historiadores, mas um biólogo as formularia? É o que questiona Robert Boyd, professor de Evolução Humana na Universidade do Estado do Arizona, EUA. Boyd não tem medo de controvérsias e, ao mesmo tempo, está muito aberto a críticas. Em um sentido quase literal. Seu livro A different kind of animal. How culture transformed our species (2017) não é apenas um veículo para as ideias de Boyd sobre o papel da cultura na evolução humana, mas também um espaço de debate.

O livro é introduzido pelo cientista político Stephen Macedo, da Universidade de Princeton, seguido por dois capítulos que expõem as ideias de Robert Boyd. Nesses capítulos, Boyd descreve como através do aprendizado social e da evolução cultural cumulativa, as sociedades se adaptam a ambientes em mudança e desenvolvem ferramentas e tecnologias cada vez mais sofisticadas. Nossa capacidade de aprender por imitação e nossa psicologia de confiança são usadas para explicar a centralidade das normas sociais e porquê e como os seres humanos têm sido há muito tempo "supercooperadores". Milênios de evolução cultural cumulativa ajudaram a criar uma vasta rede mundial de especialização e intercâmbio. Os seres humanos são os únicos que formam sociedades em que as pessoas cooperam em grandes grupos de indivíduos com escasso ou nenhum parentesco para fornecer uma enorme variedade de bens, materiais e informações. Boyd enuncia a questão: "na natureza, a cooperação em grande escala é explicada por parentesco, mas não em humanos". Como, então, poderia a seleção natural favorecer a cooperação entre estranhos? Para Boyd a 
cooperação em grandes grupos requer sistemas de normas impostas por sanções. Nas sociedades humanas, principalmente as maiores e mais complexas como as cidades, a cooperação e provisão de bens públicos depende crucialmente de sanções coercitivas impostas por instituições como a polícia e os tribunais.

Aos capítulos de Boyd seguem-se comentários críticos escritos por intelectuais de diversos matizes, condensados em quatro capítulos. O biólogo H. Allen Orr questiona se Boyd não exagera na contraposição entre o modelo do Big Brain, para o qual o êxito humano deve-se à nossa capacidade cognitiva, e o modelo de acumulação cultural defendido por ele. Afinal, essa capacidade de acumular informações depende de um cérebro bastante complexo. Uma crítica similar é esboçada por Kim Sterelny, filósofo da ciência e expert em biologia evolutiva.

A antropóloga e ecóloga evolutiva Ruth Mace elogia o enfoque multidisciplinar de Boyd na busca por respostas para a fascinante história da evolução dos primatas humanos, mas enfatiza a necessidade de provas empíricas que corroborem as hipóteses e modelos como o proposto por Boyd. Talvez a crítica mais contundente ao modelo de Boyd seja aquela formulada pelo economista Paul Seabright. Ele enfatiza uma dimensão sombria e não abordada por Boyd, a de que na verdade somos massivamente cooperantes, mas conforme Seabright, também "violentamente competitivos e maliciosamente manipuladores." Boyd retoma a palavra nos últimos dois capítulos do livro, nos quais ele comenta e tece réplicas às críticas de seus colegas.

O Homo sapiens é uma espécie de enorme sucesso adaptativo. Ele consegue sobreviver praticamente em todos os ambientes da Terra, e usa a maior parte da produção fotossintética da biosfera. Esses primatas podem até mesmo estar no espaço sideral. Isso é um fato, mas a questão mais interessante é: por quê? Além de certas peculiaridades anatômicas e fisiológicas de nossa espécie, há também a cultura, uma maneira muito eficaz de obtermos informações sobre como lidar com condições específicas. Todos nós necessitamos de comida e abrigo. Como consegui-los? Quem tem as informações? Podemos confiar em todos os membros da comunidade da mesma maneira? O modelo de Boyd (que é um grande tributo à pesquisa teórica!), apoiado pelas observações de muitas sociedades, indica que se pode aprender por imitação, mas no caso das sociedades humanas o mais importante é a capacidade de acumular conhecimentos e produzir conhecimentos a partir de novas relações e experiências.

A influência da cultura seria forte a ponto de mudar motivações biológicas? Sim. As pessoas fazem escolhas de acordo com sua própria visão de mundo, e não necessariamente por calculadoras egoístas de valores genéticos. Elas fazem opções empregando suas ferramentas culturais e sua própria inteligência. Boyd, no entanto, afirma que isso é mais do que apenas uma heurística. Talvez, o fato mais interessante sobre a nossa espécie seja o fato de que existam métodos de ensino muito diversos. Em diferentes condições ambientais esses métodos podem ser testados e checados quanto à sua eficácia. Mentiras podem ser ensinadas? Sim, mas este processo pode não ser eficaz a longo prazo. Propagandas enganosas podem ser semeadas, e isto acontece frequentemente. No entanto, em algum lugar, a verdade está constantemente revivendo. Por quê? Boyd acredita que, principalmente 
porque as crianças em alguma medida são imunizadas contra o engano, elas enxergam melhor a verdade e não têm medo de articulá-la. O rei pode estar nu, como no conto de fadas de Hans Christian Andersen.

Para Boyd, os seres humanos adaptam-se a uma grande variedade de ambientes em mudança, não principalmente aplicando a inteligência em um nível individual para resolver problemas, mas via "adaptação cultural cumulativa" e no longo prazo haveria uma seleção darwiniana entre culturas com diferentes normas sociais e valores morais. Isso quer dizer que a inteligência na escala individual é menos importante do que a inteligência coletiva, derivada do grupo.

O principal mérito de Robert Boyd é situar a cultura no âmbito da natureza. Seu livro é uma afirmação contundente de que a cultura é parte da biologia humana, opondose a um discurso frequente entre os sociólogos, aquele de que a cultura teria superado a biologia no caso do Homo sapiens. Como acertadamente pontificou o biólogo Ricardo Waizbort, quando disse que a dicotomia natureza versus cultura como chave explicativa para o comportamento humano só pode ser mantida sob o risco de ignorarmos cabalmente o que a ciência está nos dizendo. Se temos que levar as ciências sociais a sério, temos que encarar a evolução darwiniana a sério.

Assim como Waizbort, Steven Pinker reflete sobre o debate natureza versus cultura, no seu livro Tábula Rasa: A Negação Contemporânea da Natureza Humana, de 2004, onde demole o que ele denomina de "o mito da tábula rasa". De acordo com essa linha de argumentação, somos como páginas em branco ao nascer, e vamos adquirindo comportamentos de acordo com os ambientes que frequentamos. Se somos, de fato, "páginas em branco" que a sociedade preenche com as mais belas poesias ou com sórdidos contos de terror, poderíamos concluir que quanto mais acesso à educação tivesse um grupo de consumidores, menor uso fariam de seus carros, dada a maior consciência a respeito da gravidade dos problemas causados pelo uso individual dessas máquinas.

O geógrafo Paul Robbins e seus colaboradores testaram uma hipótese similar à formulada, investigando o uso de fertilizantes químicos e pesticidas em gramados de residências da cidade de Columbus. Observaram que embora a maioria dos usuários destes agroquímicos declarasse conhecer seus impactos ambientais negativos, mais da metade dos que aplicam estes insumos possuem nível superior, prática adotada por somente $24 \%$ dos que possuem apenas o ensino médio. Para equacionar a dimensão ambiental do exemplo basta afirmar que mais fertilizantes químicos são aplicados anualmente nos gramados das cidades norte-americanas do que a Índia aplica em todas as suas plantações de grãos. O que impulsiona o zelo dos norte-americanos pelos seus gramados? Além do prazer estético, o status derivado dessas paisagens meticulosamente organizadas sobrepuja qualquer outra conceituação contrária.

Não somos "páginas em branco", portanto. Na história evolutiva de nossa espécie, tendências comportamentais foram selecionadas porque eram adaptativas. $\mathrm{O}$ antropólogo Donald Brown listou mais de 200 comportamentos universais, que incluem uma mescla interessante de atitudes "nobres" como cooperação e altruísmo, por exemplo, com outras mais mundanas, como a violência, a fofoca e a troca de bens e serviços por favores sexuais. 
Um desses comportamentos é a busca por status. O prestígio, seja materializado na forma de posses, de poder, de títulos ou honrarias, é evidentemente um trunfo importante ao seu detentor. Status é uma moeda valiosa, que permite a atração de parceiros para a formação de coalizões e a conquista de metas. Nas cidades, a busca por status assume uma miríade de formas: o paisagismo com plantas exóticas, vindas de outros continentes, nas moradas mais afortunadas - "Olhe meu jardim! Eu posso despender uma pequena fortuna nele!" Ou a ostentação de bens como carros importados ou fotos de viagens postadas no Facebook. Esses comportamentos que denotam poder são potencializados nas cidades (para quê um terno Armani, se você vive isolado no Pico da Neblina?) e, mais importante, geram impactos ambientais em escala biosférica.

É um fato que a cultura é parte da biologia do Homo sapiens, e a nossa habilidade em criar e acumular cultura explica a invenção das cidades, essas máquinas de inventar máquinas, ideias, dilemas e soluções. A partir das cidades, voamos às estrelas. Feito extraordinário para uma espécie de macaco não particularmente forte, sem garras ou mandíbulas poderosas. Uma contraposição vigorosa ao enlevo de Boyd com a capacidade sui generis de acumulação cultural da espécie humana pode ser encontrada nas obras Straw Dogs: Thoughts on Humans and Other Animals, de 2013, e The Silence of Animals: On Progress and Other Modern Myths, de 2016, ambos do filósofo britânico John N. Gray. Para Gray, é verdade que os humanos são distintos dos demais animais, sobretudo pela sua capacidade em acumular conhecimento. Contudo, assim como os demais seres vivos, prossegue o filósofo, os humanos não são capazes nem de controlar seu destino, e nem de utilizar a sabedoria acumulada através dos milênios para viver melhor.

Desnudando o que denomina de mito do progresso, Gray observa que a história humana é como um ciclo que se repete, sem evoluir. Ou dito de outra forma, embora o crescimento do conhecimento seja real (ele é cumulativo, como assinala Robert Boyd), e melhorias nas sociedades e governos ocorram, elas são fugazes (de um ponto de vista histórico), períodos ilustrados são seguidos por tempos de barbárie. Assim, a história dos primatas humanos não seria uma seta inexorável rumo ao progresso ou ao declínio, mas um balanço circular inescapável entre perdas e ganhos recorrentes. Estaremos condenados sempre a uma fuga adiante? Para sempre condenados às reinvenções decorrentes da cultura, mas sempre empurrando a rocha de Sísifo? Tais como as questões formuladas por Robert Boyd em seu livro, essas não são perguntas triviais.

A fascinante epopeia dessa espécie sui generis é uma história com muitas lacunas. O livro de Robert Boyd e sua premissa de que a cultura desempenhou e desempenha um papel proeminente na evolução dos macacos humanos preenchem algumas dessas lacunas. Também merece elogios que $A$ different kind of animal não diminua o papel da biologia na nossa evolução. Boyd afirma que "a cultura faz parte da biologia humana tanto quanto nossa peculiar pélvis". Mais do que uma boutade, a assertiva do autor é uma defesa do amálgama inextricável que moldou o Homo sapiens. 